\title{
PERFIL SOCIOECONÔMICO E EPIDEMIOLÓGICO: UMA ANÁLISE DAS POPULAÇÕES ATENDIDAS POR UMA UNIDADE BÁSICA DE SAÚDE DA CIDADE DE JATAÍ (GO)
}

\author{
SOCIOECONOMIC AND EPIDEMIOLOGICAL PROFILE: NA ANALYSIS OF THE \\ POPULATIONS SERVED BY A BASIC HEALTH UNIT OF THE CITY OF JATAÍ (GO)
}

\author{
Natalli Adriane Rodrigues Souza \\ Mestranda em Geografia, Universidade Federal de Goiás- Campus Jataí \\ nattiti@gmail.com \\ Maria José Rodrigues \\ Doutora em Geografia, Universidade Federal de Goiás- Campus Jataí \\ mariarodriguesgeo@gmail.com
}

\begin{abstract}
RESUMO
O presente estudo objetivou verificar os perfis socioeconômicos e epidemiológicos das populações atendidas pela Unidade Básica de Saúde da Família Estrela D' Alva, no município de Jataí- GO. Para a coleta de dados utilizou-se o censo IBGE (Instituto Brasileiro de Geografia e Estatística) para o ano de 2010, e o E-sus (Estratégias do Sistema Único de Saúde) para o ano de 2015, buscou-se identificar os perfis epidemiológico e socioeconômico da região estudada, considerando dados referentes à renda, saneamento básico, população e diagnóstico de saúde da comunidade atendida pela UBSF local. A análise desses dados permitiu a geração de gráficos, quadros e mapas demonstrando que $44 \%$ da população vive com até 2 salários mínimos, cerca de $60 \%$ dos domicílios não recebem água tratada, $52 \%$ não tem coleta de lixo e $70 \%$ não tem rede de esgoto. Dentre a população atendida por essa UBSF quase um terço é formada por idosos, destacando-se as doenças crônicas como as mais recorrentes no ano de 2015. Diante disso, esse estudo se torna importante para a identificação dos perfis socioeconômico e epidemiológico e para a compreensão da relação que a população local estabeleceu com o local de moradia.
\end{abstract}

Palavras chave: Situação Socioeconômico. Epidemiológico. Unidade Básica de Saúde. Jataí-GO.

\begin{abstract}
The current study aimed at verifying the socioeconomics and epidemiologicals profiles of the populations served by the Basic Health Unit of the Estrela D 'Alva Family, in the city of Jataí - GO. For data collection, the IBGE census (Brazilian Institute of Geography and Statistics) was used for the year 2010, and E-sus (Strategies of the Unified Health System) for the year 2015 , the aim was to identify the epidemiological profiles and socioeconomic status of the studied region, considering data related to income, basic sanitation, population and health diagnosis of the community served by local UBSF. The data analysis permited a construction of graphs, maps and boards and they evidenced the significance of the locality surroundings for the quality of life promotion, demonstrating that $44 \%$ of the total population lives with two minimum wage income, about $60 \%$ of the houses do not get treated water, $52 \%$ do not have garbage collect and $70 \%$ do not have sewerage system. Among the served population by this UBSF almost one-third is elders, highlighting chronic diseases as the most recurrent in 2015. This study become important for the identification of socioeconomics and epidemiologicals profiles and for the comprehention of the relation that local population established with the place.
\end{abstract}

Key words: Socioeconomic Situation. Epidemiological. Basic Healt Unit Family. Jataí-GO.

Recebido em: 12/09/2017

Aceito para publicação em: 12/12/2017 


\section{INTRODUÇÃO}

A temática saúde vem cada vez ganhando mais espaço entre as pesquisas desenvolvidas no âmbito da ciência geográfica. No entanto, trata-se de um tema complexo, amplo e que vai muito além do tratamento do estado físico de um indivíduo. Guimarães (2014), menciona que a saúde além de se relacionar as condições físicas de uma pessoa, está intimamente ligada ao bem estar psicológico, emocional, mental, a fatores como renda, emprego, escolaridade, moradia, lazer, enfim, ao processo de construção da qualidade de vida.

Dessa maneira, os estudos referentes à Geografia da Saúde são de grande importância no que se refere a esse tipo de pesquisa, sabe-se que o processo saúde-doença não está relacionado somente ao fator patológico, sendo o espaço influente no surgimento e intensificação de doenças. Dessa maneira, as relações estabelecidas entre homem e espaço influem na construção de um ambiente propício ou não a manutenção da saúde dos indivíduos que o habitam.

Tomando como base esses fatores, leva-se em conta alguns autores contribuíram com a discussão do presente trabalho: Rolnik (1995), Carlos (1996), Santos (2002), Rodrigues (2007), Helman (2009), Silva (2009), Rizzo (2012), e Guimarães (2014). Tais autores levam em conta discussões acerca dos conceitos território, ambiente, saúde e cidade, sendo os mesmos importantes no desenvolvimento do presente estudo.

Diante disso e com base nas discussões referentes aos conceitos território, ambiente e saúde, vem a se considerar a região de atendimento da UBSF Estrela D'Alva, situada numa área segregada da cidade de Jataí-GO. Essa unidade de saúde tem por característica prestar atendimento à população de dois bairros próximos: um fruto de um programa habitacional (Conjunto Habitacional Estrela D' Alva), e outro resultante de uma invasão (Bairro Francisco Antônio).

O presente estudo propôs a identificação dos perfis epidemiológico e socioeconômico das populações atendidas pela UBSF Estrela D'Alva.

\section{PROCEDIMENTOS METODOLÓGICOS}

Para a elaboração desse artigo adotou-se os seguintes procedimentos metodológicos: revisão bibliográfica acerca dos temas cidade, território, ambiente e saúde. Em seguida identificou-se os setores censitários correspondentes a área pesquisada, o que de acordo como o IBGE distribuem-se ao longo dos dois bairros três setores censitários. Em seguida fez-se o levantamento de dados secundários da área pesquisada, por meio das informações do Censo Demográfico do Instituto Brasileiro de Geografia e Estatística (2010), acerca da renda, saneamento básico e população. O perfil epidemiológico da comunidade atendida pela UBSF Estrela D'Alva foi identificado através dos dados disponibilizados pela Secretaria Municipal de Saúde de Jataí, através do E-sus para o ano de 2015. Tal sistema apresenta um registro de dados referentes a atendimentos e acompanhamentos de pacientes nas UBSFs.

A análise dos dados coletados permitiu a geração de gráficos e quadros, no software Excell e mapas por meio do software ArcGis 10.1. Após a tabulação dos dados realizou-se trabalho de campo na área para verificação das condições do ambiente. Em seguida realizou-se a análise e discussão dos resultados.

\section{CARACTERIZAÇÃO DA ÁREA DE ESTUDO}

Localizado no extremo sul da cidade de Jataí (Mapa 1), a UBSF Estrela D' Alva é responsável por oferecer atendimento à população dos bairros Conjunto Habitacional Estrela D' Alva e Francisco Antônio, localizados em uma região que apresenta segregação sócio espacial na cidade de Jataí, sendo separados do restante da área urbana pela rodovia $\mathrm{Br} 364$, estando próximos a uma área industrial e rural.

Os dois bairros são considerados razoavelmente jovens levando em conta que os bairros mais antigos da cidade datam da década de 1950, enquanto os mesmos surgiram entre o fim da década de 1980 e o início da década de 1990 (SILVA, 2009). Os mesmos surgiram em função de problemas relacionados ao número limitado de moradias na cidade. 


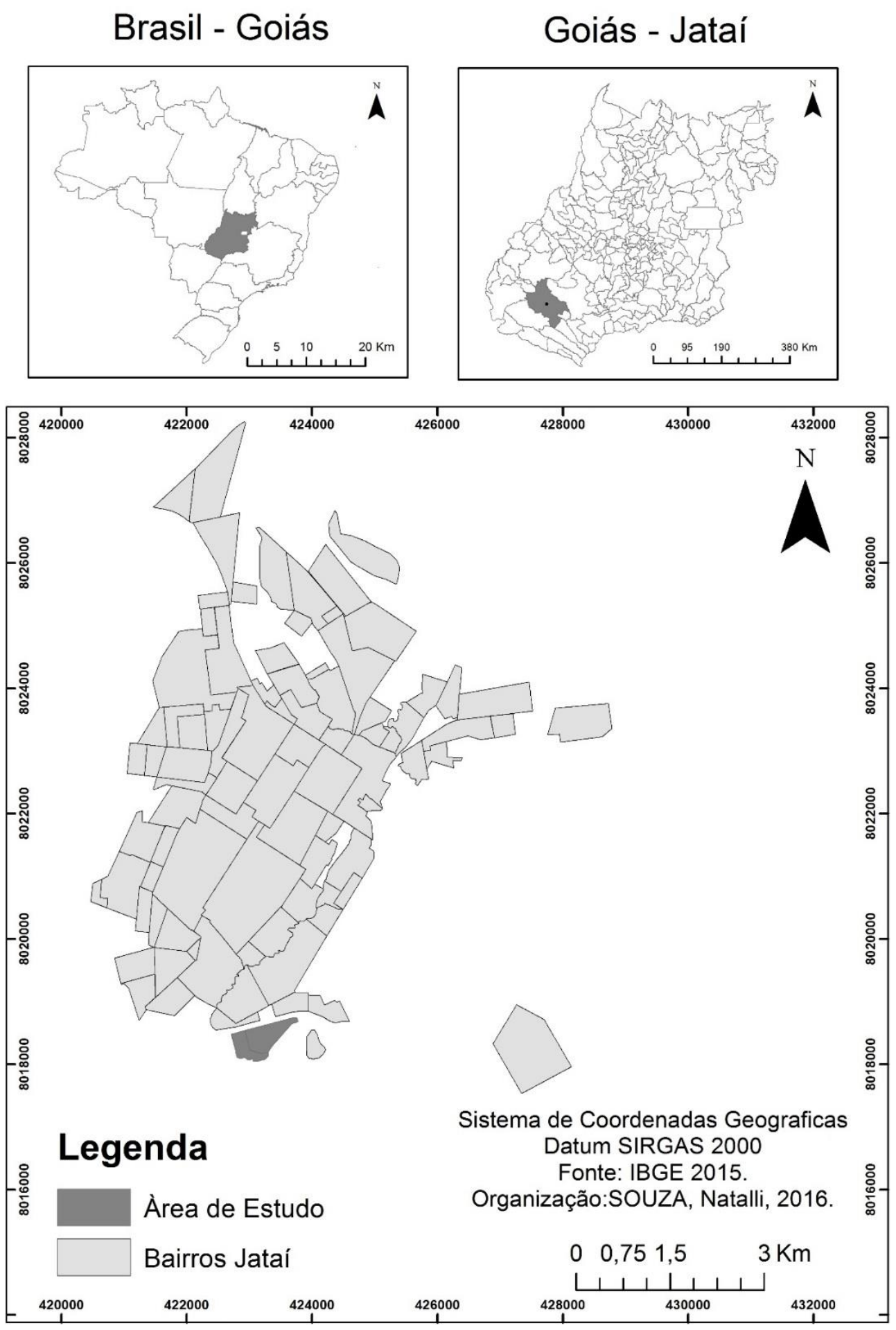

Fonte: IBGE (2015). Organização: Souza, 2016.

No final dos anos de 1980 por conta do déficit habitacional no município, o governo municipal em parceria com a Caixa Econômica Federal propôs um programa de financiamento habitacional 
construindo 496 casas em estrutura simples, apenas no contra piso, contendo um banheiro e um cômodo (foto1).

No entanto, diante de dificuldades referentes ao pagamento das parcelas das casas financiadas, muitos de seus moradores ficaram inadimplentes sendo obrigados a abandonarem as mesmas. A partir desse momento surge o bairro Francisco Antônio, como essas famílias não tinham onde morar começaram a ocupar uma porção de terra, pertencente à prefeitura municipal, vizinha ao conjunto Estrela D' Alva, o atual bairro Francisco Antônio. As casas antes abandonadas por seus moradores também passam a ser invadidas por pessoas que não tinham onde morar.

Foto 1 - Modelo das primeiras casas do Conjunto Habitacional Estrela D' Alva, 2016

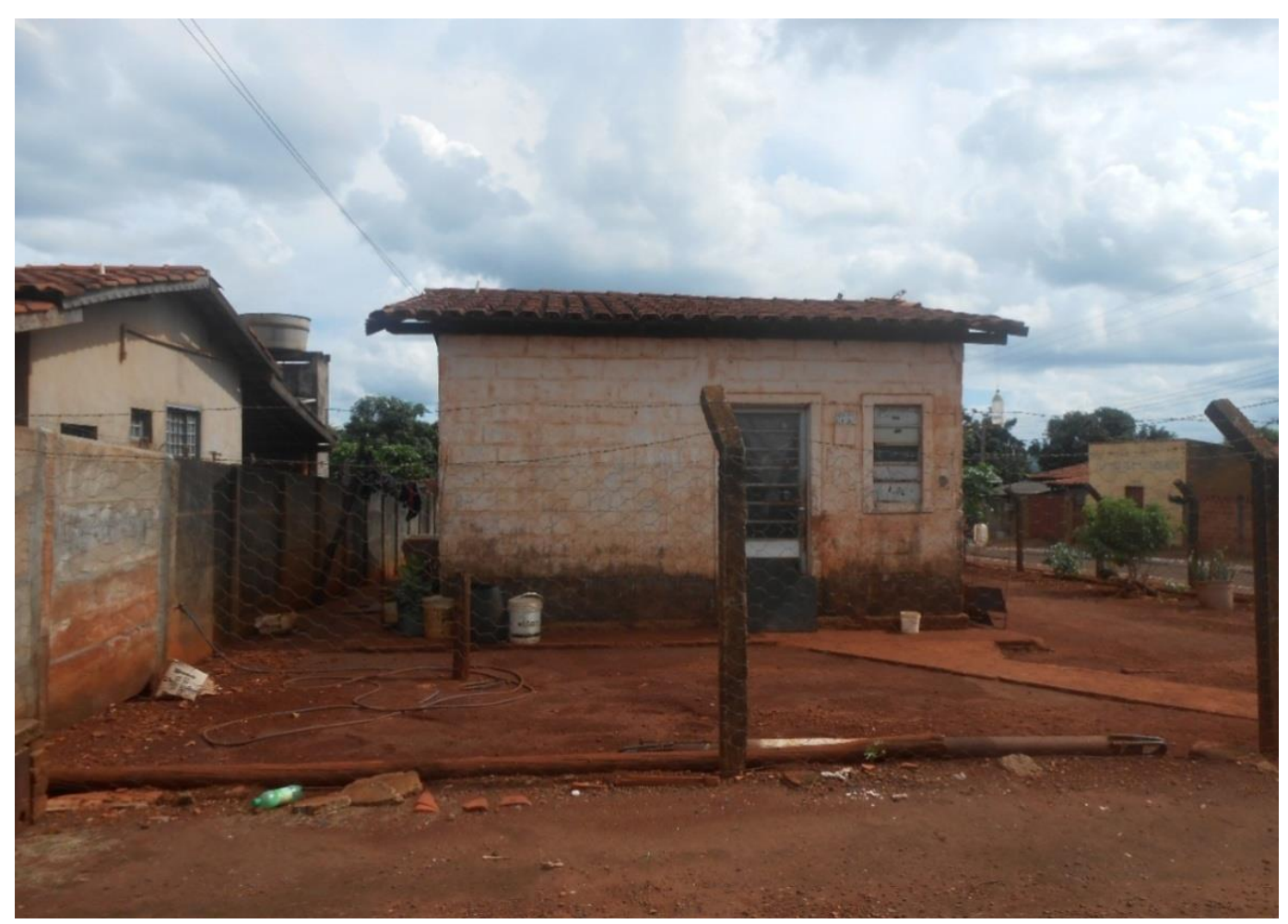

Fonte: Souza, 2016.

Decorridos esses fatos o município se vê diante de um problema de habitação e propõe assim, em parceria com o governo do Estado de Goiás, a quitação das dívidas dos moradores inadimplentes, cedendo também a porção do bairro Francisco Antônio aos moradores que ali ocuparam.

Atualmente, os dois bairros estão parcialmente ocupados, com um número escasso de terrenos baldios. Porém, ainda abrigam uma população carente que sofre com a falta de alguns serviços públicos, com dificuldades quanto à mobilidade por conta da $\mathrm{Br}$. 364 que separa os bairros do restante da cidade e da grande distância existente entre os mesmos e a área central, onde abriga os serviços públicos mais essenciais.

Apesar das carências referentes à infraestrutura, ao longo dos anos a população residente no local alcançou algumas implementações públicas sendo elas de grande importância para a manutenção da qualidade de vida dos seus habitantes. Tais implementações foram realizadas na área do Conjunto Habitacional Estrela D' Alva, sendo, compartilhados com o Bairro Francisco Antônio, como é demonstrado no quadro seguinte. 
Quadro 1 - Implementações Realizadas No Conjunto Habitacional Estrela D’ Alva

\begin{tabular}{|r|l|}
\hline \multicolumn{1}{|c|}{ Ano } & \multicolumn{1}{c|}{ Implementação } \\
\hline 1992 & Inauguração da escola. $1^{\circ}$ a $3^{\circ}$ séries. \\
\hline 1993 & Extensão da $4^{\circ}$ série \\
\hline 1993 & Abastecimento de água no bairro. \\
\hline 1993 & Construção da creche. \\
\hline 1993 & Instalação da UBSF. \\
\hline 1996 & Construção do centro comunitário. \\
\hline 2006 & Extensão da $2^{\circ}$ fase do ens. fundamental. \\
\hline 2013 & Extensão EJA (Educação para jovens e adultos). \\
\hline Indeterminado & Ampliação da UBSF. \\
\hline Indeterminado & Faixas de sinalização nas vias percorridas pelo transporte coletivo. \\
\hline Indeterminado & Gramado no campo de futebol do bairro. \\
\hline Indeterminado & Iluminação da Avenida Manoel Capado. \\
\hline Indeterminado & Instalação de manilhas próximas à escola. \\
\hline Indeterminado & Praça. \\
\hline Indeterminado & Tartarugas para sinalização do trânsito na entrada do bairro. \\
\hline Indeterminado & Academia ao ar livre. \\
\hline
\end{tabular}

Fonte: Prefeitura Municipal de Jataí. Organização: Souza, 2016.

\section{REFERENCIAL TEÓRICO}

Ao tratarmos da temática saúde, o território assume um papel importante, isso porque, além de apresentar limites políticos e administrativos, o território se apresenta como uma criação coletiva, resultado das ações humanas, apresentando características próprias de seu tempo, mas, também resquícios de tempos passados, chamados também de rugosidades (SANTOS, 2002).

Em relação a área urbana de Jataí, tais rugosidades podem ser verificadas com base na observação dos elementos da paisagem da cidade, como destaca Silva (2009):

Revelando uma dimensão do espaço produzido percebe-se, através da paisagem urbana de Jataí, a sobreposição de tempos diversos. Elementos pretéritos, que resistem à velocidade da sociedade atual, trazem informações importantes para a compreensão da cidade e das relações nela produzidas. (SILVA, 2009, p. 146).

Assim, as rugosidades presentes ao longo do território são, dessa maneira, resultantes de todo o processo de técnica empregado na criação do mesmo. O emprego de diferenciadas técnicas virá a definir o uso e função desse território e, de acordo com o tipo de técnica empregado, territórios próximos podem vir a apresentar funções diferenciadas.

Os variados usos para diferentes territórios e a técnica empregada, o ambiente da cidade se destaca: sendo composta por espaços heterogêneos com funções diferenciadas, a cidade pode ser considerada como um quebra cabeças (ROLNIK, 1995). Ao mesmo tempo em que esse ambiente une grupos também os separa, abrangendo dessa forma espaços homogêneos em seu interior, mas também heterogêneos, se comparados a outros espaços.

Considerando as diferenças presentes ao longo do espaço da cidade, vem-se a analisar um território em questão: a área de atendimento da UBSF Estrela D' Alva, no município de Jataí- GO. Essa área trata-se de uma das peças do quebra cabeça que Rolnik (1995) trata em seu livro "O que é cidade?". Por conta da segregação, é uma área diferente das demais áreas da cidade, mas que, no entanto, se encaixa no tecido urbano de Jataí. 
A área em questão apresenta uma segregação sócio espacial influenciada principalmente pela questão socioeconômica que vem a refletir nos diferentes usos, valores e ocupação do solo na cidade de Jataí, fazendo dessa região um ambiente que apresenta certas carências. Considerando as carências presentes em determinado ambiente, vem a se considerar as influências que tem as condições do mesmo para a manutenção da qualidade de vida.

Helman (2009), ao tratar dessas carências considera a pobreza como o fator mais prejudicial à saúde, fazendo assim a seguinte ponderação:

\begin{abstract}
Os fatores econômicos e a desigualdade social são algumas das causas mais importantes de má saúde, pois a pobreza pode resultar em desnutrição, condições de vida em aglomerações, roupas inadequadas, níveis ruins de educação, casa ou trabalho situados em áreas com riscos ambientais maiores (como nas proximidades de fábricas que possuem resíduos tóxicos), bem como exposição à violência física e psicológica, estresse psicológico e abuso de drogas e de álcool. (HELMAN, 2009, p. 14)
\end{abstract}

Assim, a pobreza influi na condição do ambiente, na condição de moradias, no onde e como morar, na alimentação, o que por consequência afeta diretamente a saúde. Por esse motivo, Rodrigues (2007) trata da importância de políticas que visem suprir as diferenças intra-urbanas a fim de produzir saúde e qualidade de vida.

No entanto, não é apenas o tratamento do ambiente por meio de políticas públicas que vem a suprir as necessidades do cuidado com o ambiente. Torna-se válido destacar que, anterior a própria criação de políticas públicas que visem à manutenção de determinado território já existia o vínculo entre o indivíduo e o ambiente/ lugar onde vive. Dessa maneira, o a apropriação do indivíduo sobre o lugar em que habita, vem a criar um vínculo de afetividade do mesmo sobre seu lugar de habitação, se assumindo como base para reprodução da vida e das relações humanas (Carlos, 1996).

Dessa forma, além da produção de um ambiente saudável por meio do Estado, é interessante destacar que o próprio indivíduo enquanto cidadão tem uma responsabilidade sobre o local onde mora. Rizzo (2012) já destaca o interesse do Estado em promover campanhas para manutenção de saúde por meio do ensino em escolas públicas, reconhecendo no cidadão a responsabilidade com a manutenção da saúde a partir de hábitos simples, como cuidar do local onde vive.

\title{
ANÁLISE E DISCUSSÃO DOS RESULTADOS
}

Nos dois bairros estão localizados três setores censitários. Dessa forma, para melhor entendimento dos setores distribuídos nesta área, os mesmos serão chamados de acordo com seus três últimos dígitos.

Com base nas análises dos dados disponibilizados pelo censo IBGE (2010), se identificou que o setor 049 abrange grande parte do Conjunto Habitacional Estrela D' Alva apresentando características bastante semelhantes em seu interior, com uma população estimada de 291 pessoas. O setor 050 abrange parte dos bairros Estrela D' Alva e uma parcela Francisco Antônio abrigando 187 pessoas residentes e o setor 051 abrange apenas o território referente ao bairro Francisco Antônio, residindo em seu interior 291 indivíduos de acordo com o censo IBGE (2010) (mapa 2).

Ao longo destes setores censitários se distribuem obras realizadas por meio do poder público a fim de proporcionar a população residente no local uma melhoria na qualidade de vida. Entre tais implementações se destacam uma linha de transporte público regular, quadras de esportes, escola, UBSF, entre outros. O mapa 2 demonstra a distribuição de algumas dessas obras ao longo dos três setores censitários, sendo que tais implementações se concentram principalmente no Conjunto Habitacional Estrela D' Alva.

O trabalho procurou analisar as implementações públicas distribuídas ao longo dos setores censitários, em relação à oferta de saneamento básico, tais como, rede de esgoto, distribuição de água tratada e coleta de lixo. A coleta e análise dos dados evidenciou que os três setores censitários pesquisados apresentam algumas carências no que diz respeito a tais serviços.

Tais implementações atuam de forma a melhorar a vida dos habitantes de certa região, primeiramente destaca-se a distribuição de água ao longo dos bairros para o ano de 2010, evidenciou-se que em relação aos três setores censitários, 40\% dos domicílios (o equivalente a 109 residências) recebem água tratada, sendo que os demais domicílios contam principalmente com o uso de água retirada de poços, ou outras formas de abastecimento, o que constitui um problema, já 
que, podem ocorrer doenças de veiculação hídrica em virtude da qualidade ruim da água. O gráfico 1 demonstra como ocorre a distribuição do abastecimento de água ao longo dos bairros.

Mapa 2 - Cidade de Jataí: setores censitários selecionados, 2015

\section{Brasil - Goiás}
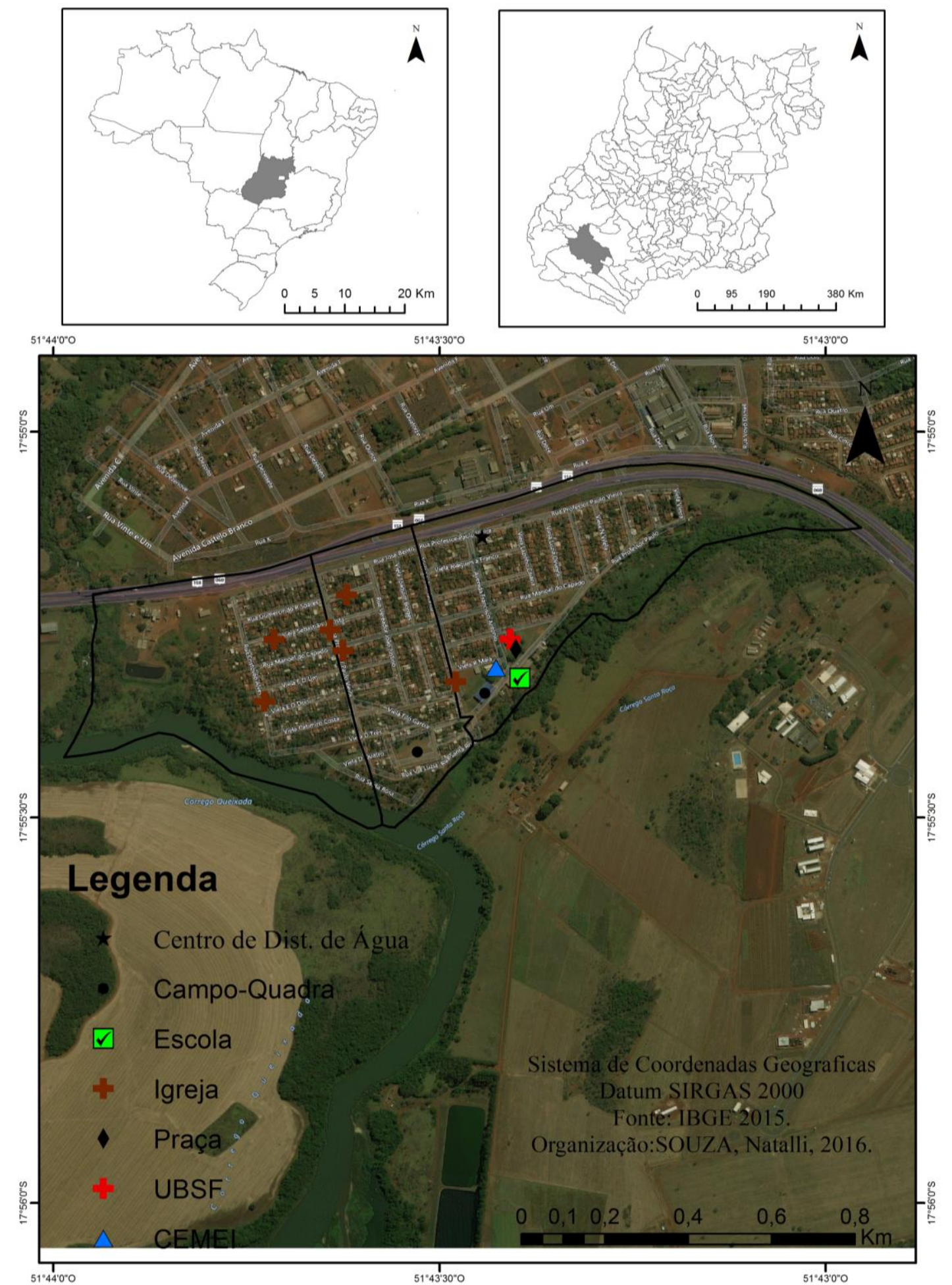

Fonte: IBGE (2010). Organização: Souza, 2016.

$11^{\circ} 43^{\circ} 00$ 
Gráfico 1 - Setores Censitários selecionados: distribuição de água, 2010

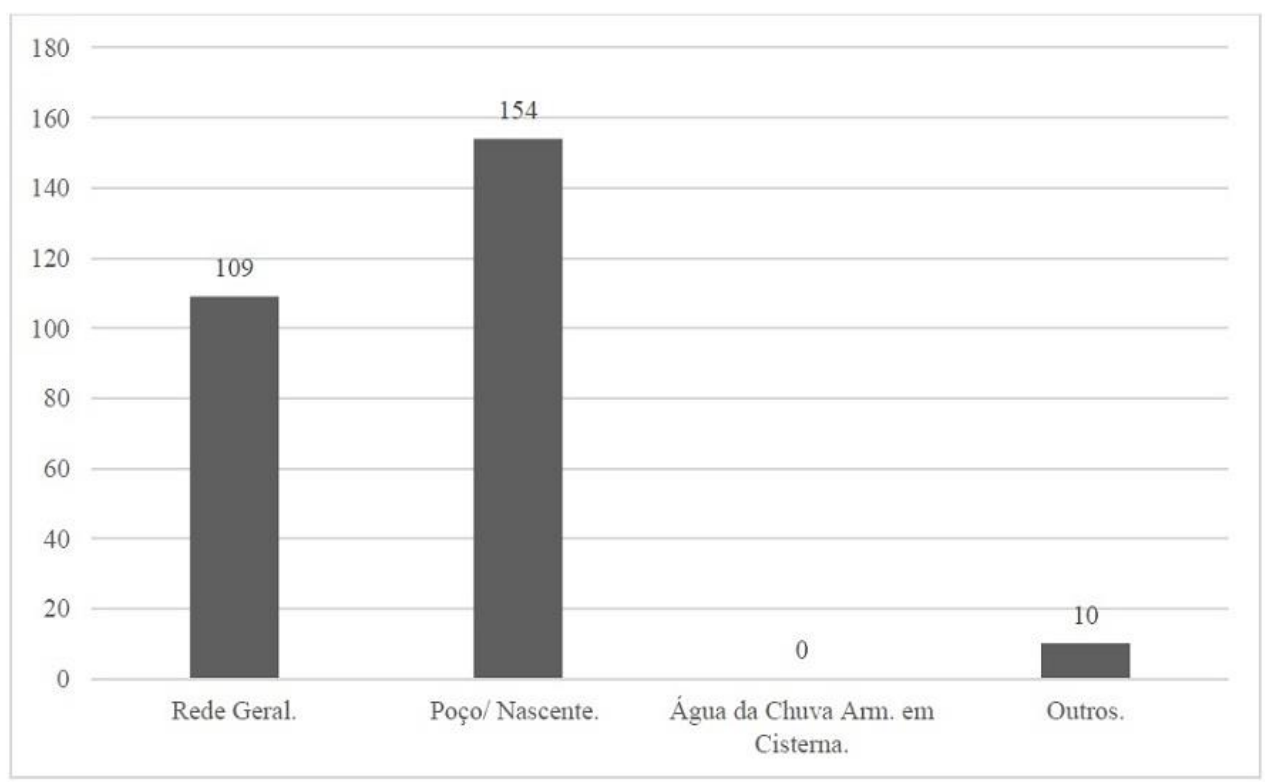

Fonte: IBGE (2010). Organização: Souza, 2016.

Além da carência quanto ao abastecimento de água tratada em todos os domicílios outra carência evidenciada ao longo dos bairros diz respeito ao tipo de esgotamento sanitário, pois cerca de $30 \%$ dos domicílios (79 domicílios) descartam adequadamente o seu esgoto, enquanto $70 \%$ dos domicílios (186 residências) utilizam outras formas de esgotamento sanitário, como fossa rudimentar ou descarte diretamente no curso d'água. (Gráfico 2).

Gráfico 2 - Setores Censitários: esgotamento sanitário, 2010

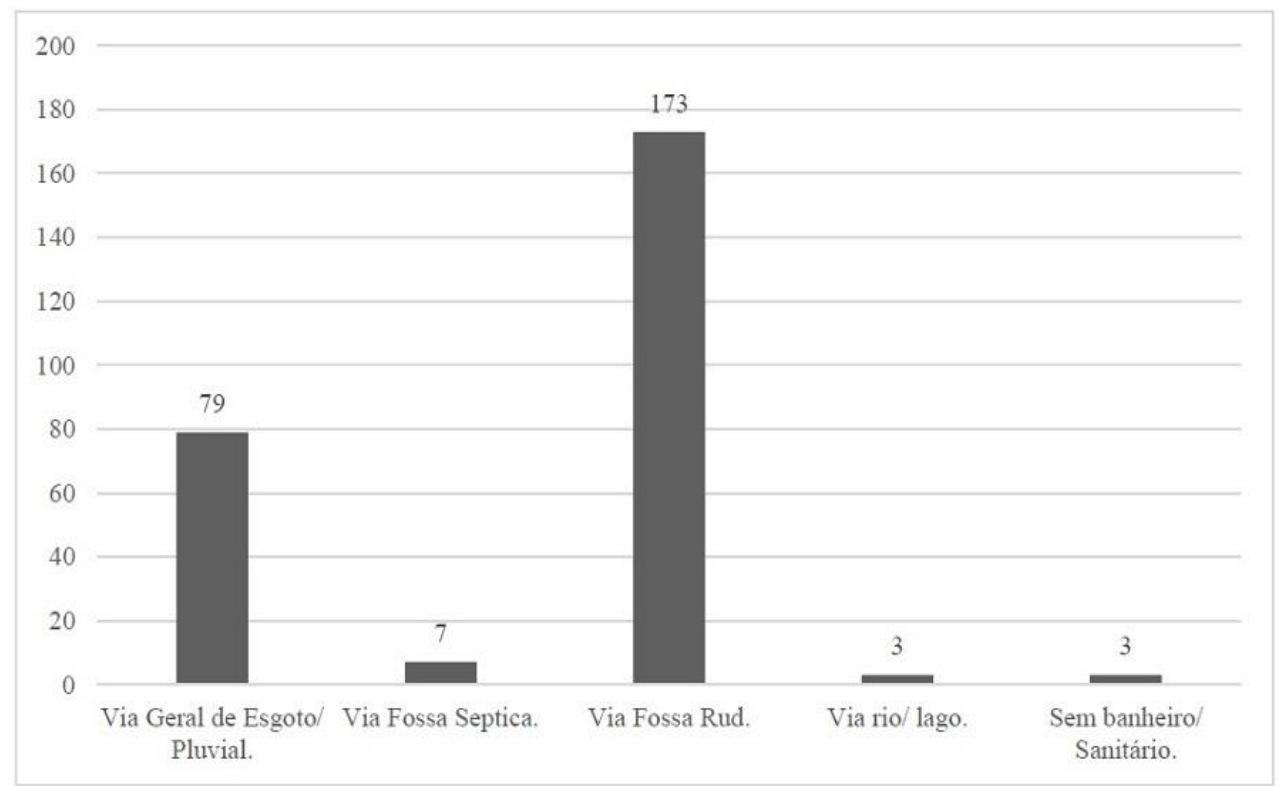

Fonte: IBGE (2010), Organização: Souza, 2016. 
Diante do grande número de residências sem o destino adequado para o esgoto sanitário doméstico, tal realidade se torna um grande problema, pois o destino inadequado do esgoto, além de contaminar o solo, a água e alimentos, se configura como um grande risco para a saúde humana, podendo ocasionar doenças graves (Scarlato e Pontin, 1999).

No entanto, no que se refere a práticas saudáveis de saneamento básico a coleta adequada do lixo também se constitui como um fator primordial para a manutenção da saúde. Considerando a importância desse serviço, o gráfico 3 demonstra como o mesmo se ocorre ao longo da área estudada.

Gráfico 3 - Setores Censitários: descarte do lixo domiciliar, 2010.

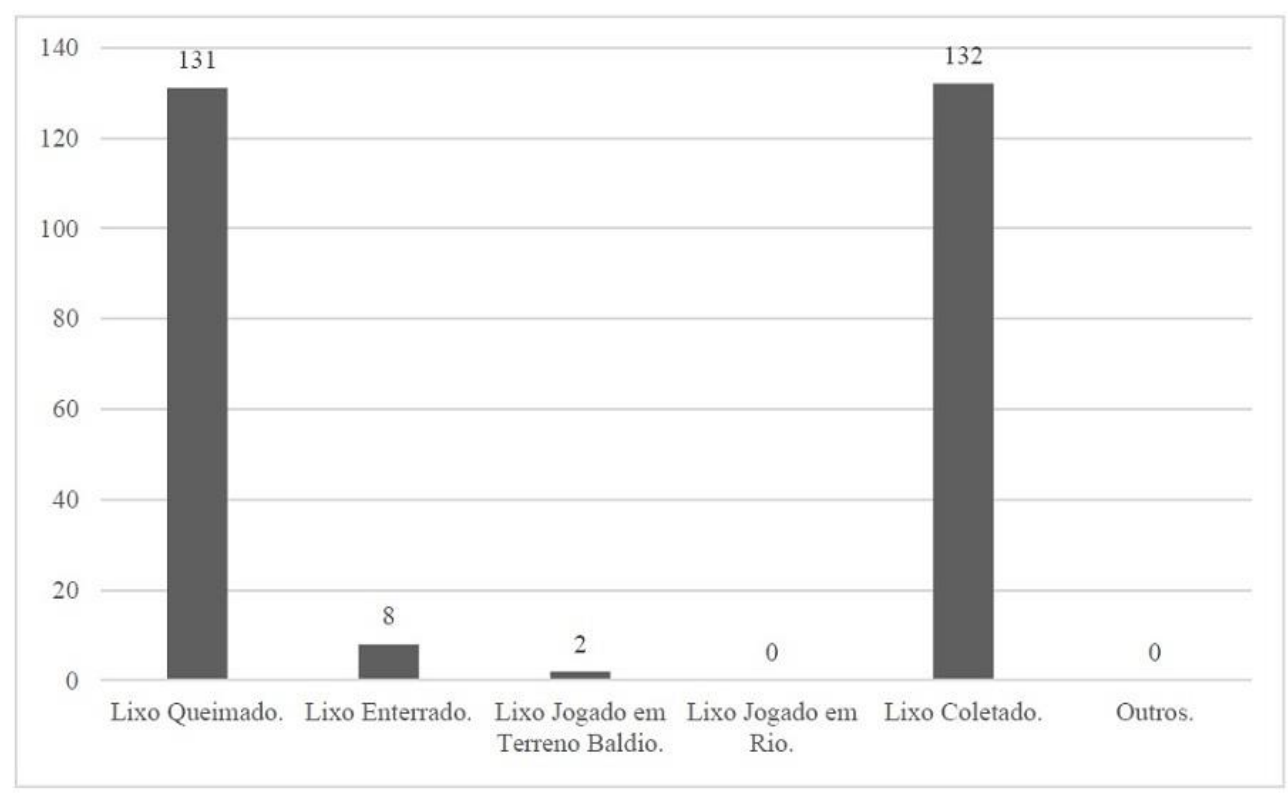

Fonte: IBGE 2010. Organização: Souza, 2016.

Como demonstrado no gráfico 3 , cerca de $48 \%$ do lixo das residências é descartado de forma devida (o que equivale a coleta do lixo pelo caminhão da prefeitura em 132 residências) e, os outros $52 \%$ dos domicílios (141 residências) contam com outras formas de descarte do lixo, sendo que $48 \%$ vê na incineração do lixo a maneira mais viável de sanar o problema. De fato, considerando os malefícios causados pelo mesmo entre as diversas possibilidades de descarte, essa se torna a mais viável já que o armazenamento do mesmo, além de trazer mau cheiro e sujar o ambiente, atrai vetores de diferentes doenças, como ratos, baratas, formigas, mosquitos, entre outros.

É importante relatar, que a própria incineração do lixo pode trazer prejuízos à saúde humana, principalmente doenças de ordem respiratória, no entanto, considerando a realidade estudada a incineração do lixo torna-se assim, a maneira encontrada pela população para solucionar o problema do "que fazer com o lixo".

Em relação aos dados referentes a rendimento nominal mensal, observou-se que $44 \%$ da população recebe entre 1 a 2 salários mínimos (SM), as pessoas que tem rendimento superior a 2 salários mínimos somam um total de $33 \%$ da população, sendo que os $23 \%$ restantes tem um rendimento inferior a 1 salário mínimo por mês.

Em relação aos valores apresentados quanto ao rendimento e as próprias condições de moradia da população local verificou-se que a mesma, pertence a uma classe econômica baixa, algo que também é observado com base no comparativo do rendimento do bairro e da população total da cidade de Jataí, onde $69 \%$ dessa população têm rendimento nominal mensal acima de dois salários 
mínimos (IBGE,2010), valor superior a média da área estudada, reforçando a questão da segregação socioeconômica tratada nessa pesquisa.

Para se conhecer o perfil etário da população atendida pela UBSF Estrela D' Alva optou-se por coletar os dados através do banco de dados do E-Sus, para o ano de 2015. A análise dos dados evidenciou que $14 \%$ da população cadastrada pela equipe de saúde tem até nove anos, $12 \%$ estão na faixa etária de 10 à 19 anos, $34 \%$ de 20 à 59 anos e $31 \%$ da população atendida pela UBSF é formada por idosos, representando quase $1 / 3$ dos atendimentos prestados nessa unidade de saúde.

Levando em conta a população atendida ao longo do ano de 2015 pela UBSF, bem como suas necessidades verificou-se que os chamados procedimentos consolidados, como aferição de pressão, temperatura, peso, altura e glicemia, responderam por $77 \%$ dos atendimentos na UBSF Estrela D'Alva e $21 \%$ estão relacionados à saúde bucal.

Uma parte importante dos acompanhamentos de pacientes da equipe de saúde da família da área de estudo se referem ao tratamento de crianças (271 crianças atendidas em 2015) e indivíduos portadores de doenças crônicas (106 casos de diabetes e 548 casos de hipertensão). Se observa também que no ano de 2015 foi verificado um número razoável de pessoas identificadas com doenças referentes à saúde mental considerando o número de pessoas residentes em ambos os bairros atendidos pela UBSF, conforme demonstra o quadro 2 .

Quadro 2 - Acompanhamentos realizados pela equipe da UBSF Estrela D' Alva, 2015

\begin{tabular}{|l|r|}
\hline \multicolumn{2}{|c|}{ Tipos de Acompanhamento } \\
\hline Condicionalidades do Bolsa Família. & 5 \\
\hline Condições de Vulnerabilidade Social. & 0 \\
\hline Criança. & 271 \\
\hline Domiciliados/ Acamados. & 39 \\
\hline Gestante. & 70 \\
\hline Pessoa com Asma. & 3 \\
\hline Câncer. & 19 \\
\hline Desnutrição & 4 \\
\hline Diabetes. & 106 \\
\hline DPOC/ Enfisema. & 2 \\
\hline Hanseníase. & 0 \\
\hline Hipertensão. & 548 \\
\hline Outras Doenças Crônicas. & 1 \\
\hline Tuberculose. & 1 \\
\hline Pessoa em reabilitação ou com Deficiência. & 12 \\
\hline Puérpera. & 10 \\
\hline Recém Nascido. & 6 \\
\hline Saúde Mental. & 17 \\
\hline Sintomáticos Respiratórios. & 0 \\
\hline Tabagista. & 0 \\
\hline Usuário de Álcool. & 6 \\
\hline Usuário de Outras Drogas. & 1 \\
\hline
\end{tabular}

Fonte: Relatório E-Sus: UBSF Estrela D’ Alva, 2015. Organização: Souza, 2016. 
Os casos de doenças crônicas não-transmissíveis (DCNT), nos chamaram atenção já que, a área analisada apresenta alto número de acompanhamentos de indivíduos para as chamadas DCNT, como diabetes e hipertensão, um problema enfrentado pela equipe de saúde da área analisada, sendo necessários projetos que visem a conscientização da população, já que esse tipo de doença vai além do quadro genético da pessoa, dizendo respeito também as condições alimentares, à prática de atividades físicas, entre outras (Duncan et al, 2012).

Em relação às doenças crônicas identificadas na população atendida pela UBSF, bem como os dados referentes a rendimento pressupõe-se que muitos casos referentes às doenças crônicas tem uma base econômica: diante de tantas obrigações a fim de se viver de forma digna (moradia, vestimentas, alimentação, entre outros.), nem sempre o indivíduo tem recursos suficientes para optar por uma alimentação de qualidade, o que acaba por refletir na sua saúde, e no surgimento desse tipo de doença.

Ainda em relação ao atendimento ofertado por essas unidades de saúde, as visitas domiciliares também se destacam por levar informação com relação à consultas e exames, monitoramento e acompanhamento do cartão de vacinas e dos condicionantes do Bolsa Família e atendimentos às pessoas que não podem se deslocar até a unidade de saúde, como os acamados.

Com relação às visitas para monitoramento e acompanhamento de doenças condicionadas ao ambiente, se observa no ano de 2015, foram confirmados 12 casos de dengue, o equivalente a menos de $1 \%$ da média total de casos registrados na cidade, sendo então este número considerado pequeno para a realidade de Jataí, já que até o período de Outubro de 2015 foram confirmados 4.972 casos de dengue na cidade afora os casos registrados na área estudada.

O pequeno número de casos de dengue pode ser resultado das campanhas de orientação realizadas pela UBSF, para prevenção da mesma, já que o ambiente local é propício para o contágio e transmissão da dengue, (rio e mata próximos, carência em implementações referentes a saneamento básico, entre outros). No entanto, é relevante destacar que na área estudada e também no restante da cidade de Jataí podem existir casos da doença não notificados nas UBSF, no entanto, a análise dos dados baseou-se nos casos notificadas na UBSF estudada.

O pequeno número de casos de dengue notificados na área estudada, para o ano de 2015, também está relacionado ao cuidado da população com o ambiente em que vive, pois esse se tornou essencial para a manutenção de um ambiente saudável mesmo diante de diversas carências em infraestrutura. Tais práticas acabaram por influenciar a produção de saúde nesse ambiente bem como a melhoria da qualidade de vida dos moradores ali residentes.

Esse cuidado evidenciado se destaca como um vínculo afetivo entre indivíduo e local de moradia, refletindo no cuidado com o ambiente para a produção de saúde, fato evidenciado ao longo das visitas em ambos os bairros: ruas limpas, terrenos baldios sem lixo, entre outros.

\section{CONSIDERAÇÕES FINAIS}

Ao se realizar estudos referentes à Geografia da Saúde denota-se que os mesmos não devem ser dados como acabados, com resultados inalterados, tais estudos partem das relações efetivadas entre indivíduo e espaço, sendo dessa forma algo que está em constante transformação.

No presente estudo não foi possível observar a interferência direta do ambiente sobre a condição de saúde dos indivíduos, sendo esta também afetada por condições socioeconômicas que por sua vez afetam a condição de saúde de uma população. Neste contexto, deve-se considerar que não somente o ambiente afeta a condição de saúde de indivíduos, mas também o sentimento de pertencimento ao lugar, o vínculo afetivo.

A área de estudo apresentava poucas condições para a efetivação de um ambiente saudável, apresentando $60 \%$ dos domicílios sem água tratada, $52 \%$ sem coleta de lixo, $70 \%$ sem rede de esgoto, se mostrando como um ambiente carente no que se refere a saneamento básico. No entanto, mesmo diante de tais carências os resultados apresentados pela UBSF revelaram um número pequeno de doenças condicionadas ao ambiente. Diante de tais verificações se nota a importância do cuidado do cidadão com o seu lugar de moradia.

Assim, o vínculo de pertencimento e de afetividade entre o morador e o lugar onde reside se torna de grande relevância para a efetivação de um ambiente saudável. O cuidado, a preocupação, o apego 
existente entre indivíduos e o ambiente onde vivem se tornam também essenciais para a produção de saúde, sendo essas, ações anteriores à própria efetivação de políticas públicas para a manutenção da saúde.

\section{REFERÊNCIAS}

CARLOS, Ana Fani Alessandri. O lugar no/ do mundo. São Paulo: HUCITED Ltda, 1996.

DUNCAN, Bruce Bartholow et al. Doenças Crônicas Não Transmissíveis no Brasil: prioridade para enfrentamento e investigação. Rev. De Saúde Pública. n. 46, 2012, p. 126-134.

GUIMARÃES, Raul Borges; PICKENHAYN, Jorge Amâncio; LIMA, Samuel do Carmo. Geografia e saúde sem fronteiras. 1. Ed. Uberlândia (MG): Assis Editora, 2014.

HELMAN, Cecil G. Cultura, Saúde e Doença. Tradução de Ane Rose Bolner. 5 ed. Porto Alegre: Artmed, 2009, $432 \mathrm{p}$.

PREFEITURA MUNICIPAL DE JATAÍ. Unidades de saúde. Disponível em:

http://www.jatai.go.gov.br/index.php?option=com_content\&view=article\&id=990\&ltemid=271 Acesso em: 18 Mar. 2016.

RIZZO, Deisi das Graças. Saneamento e Sertão. Guarapuava (PR): Unicentro, 2012.

RODRIGUES, Maria José. Espaço e serviços de saúde pública em Uberlândia (MG): Uma análise do acesso ao Programa de Saúde da Família- Núcleo Pampulha. Dissertação (Mestrado em Geografia). Universidade Federal de Uberlândia, Uberlândia (MG). 2007. 199 f.

ROLNIK, Raquel. O que é cidade? São Paulo: Brasiliense, 1995.

SANTOS, Milton. A Natureza do Espaço. São Paulo: Edusp, 2002.

SCARLATO, Francisco Capuano; PONTIN, Joel Arnaldo. Ambiente Urbano. São Paulo: Atual, 1999.

SILVA, Márcio Rodrigues. Desvelando a cidade: segregação socioespacial em Jataí- Go. Tese (Doutorado em Geografia). Universidade Federal de Goiás, Instituto de Estudos Sócio-Ambientais, Goiânia (GO). 2009. 205 f. 